for his primary duty was to relieve blindness as well as administration and teaching, and with his experienced pathological background he worked in his laboratory often until 2 a.m. He organised, and made many contributions to, the pathology museum of the Elliot School, which opened just before he took charge. Most of his leaves were spent in postgraduate study with Vogt, Parsons, Treacher-Collins, and Barraquer in Europe, but after 1926 he became closely attached to American ophthalmologists and pathologists including Knapp, Wheeler, and Verhoeff, whose wcrk and friendship impressed him tremendously. In 1929 he was appointed CIE.

On retirement from the IMS in 1938 Wright was for a while lecturer to the London School of Hygiene and Tropical Medicine, and in the same year Trinity College, Dublin, conferred on him the honorary $\mathrm{MCh}$. When war broke out he took over the ophthalmic department of the Cambridge Military Hospital, Aldershot.

Wright's publications are numerous and authoritative, and his vast experience in cataract and glaucoma surgery was acclaimed in America and Australia. In 1946 he had to decline mastership of the Oxford Ophthalmological Congress on grounds of health. At the age of 73 he developed chronic simple glaucoma, which he diagnosed himself. It was effectively treated by surgery, and eight months before his death he required cataract extractions. In his old age his hobby was reading up modern advances in general medicine. With his extremely busy professional life Wright had little time for social functions, but he enjoyed fishing and big game shooting from time to time and hunted tiger in what he called the proper way -on foot.

As a man Robert Wright was a delightful and stimulating companion, full of life and interest. Those who got to know him well believe that, though not the most renowned, he was by quite a margin the best of the distinguished band of ophthalmologists who served India so well in the days of the British Raj. In later years his fame may have become dim in Britain, but in Madras he is to this day accorded the greatest respect.' His laboratory continues much as he left it in 1936, and good work, especially on fungus infections, has been done by Indian ophthalmo-pathologists who followed him. Wright enjoyed a happy marriage; there were no children.

\title{
Correspondence
}

\section{Urokinase in the management of vitreous haemorrhage}

TO THE EDITOR, British Journal of Ophthalmology SIR, In a recent article Chapman-Smith and Crock (1977) enroneously reported data from our report of 100 consecutive pars plana vitrectomies (Peyman et al., 1976a). According to their Table 6 vision improved in only $14 \%$, remained the same in $76 \%$, and worsened in $10 \%$ of our patients' eyes. In fact, as our original publication indicates, vision improved in $\mathbf{7 1} \%$, was unchanged in $19 \%$, and became worse in only $10 \%$. These results were reinforced in a subsequent article (Peyman et al., $1976 b)$ in which we described another series of vitrectomies in 125 eyes with diabetic vitreous haemorrhage. In the second group visual acuity was improved in $66 \%$, unchanged in $24 \%$, and worse in $10 \%$ of eyes.

In order to calculate these percent changes, we utilised a new functional classification of visual acuity (Peyman et al., 1976a, b). Chapman-Smith and Crock indicated that they had recategorised our information using their own classification of visual acuity, but this could not have been performed without our original raw data. Using the visual acuity classification of Chapman-Smith and Crock, it is possible to show the desired, correct data (Table 1). These data from Peyman et al. (1976a) actually show visual improvement that was equal to or more than 2 Snellen lines in $59 \%$ and that was equal to 1 line of improvement in $12 \%$ of eyes. There was no change in $19 \%$, and there was reduced acuity in $10 \%$ of eyes (Table 1). Whether categorised by our acuity classification or by that of Chapman-Smith and Crock, the data obviously suggest that our results of treating vitreous haemorrhage by surgical vitrectomy are superior to those obtained through the use of intravitreal urokinase (Table 1 vs. Table 2).

In addition, the authors also stated erroneously that in another article of ours (Koziol et al., 1975) only 4 speciosa monkeys were used to study the effect of intravitreal urokinase on experimental vitreous haemorrhage. As reported in the original publication, a total of

Table 1 Data from Peyman et al. (1976a)

\begin{tabular}{|c|c|c|c|c|c|}
\hline & \multirow{2}{*}{$\begin{array}{l}\text { No. of } \\
\text { eyes }\end{array}$} & \multicolumn{4}{|c|}{ Improved visual acuity (Snellen chart) } \\
\hline & & $\geqslant 2$ lines & 1 line only & Unchanged & Worse \\
\hline Diabetics & 52 & $30 \begin{array}{l}(\%) \\
(57 \cdot 6)\end{array}$ & $7 \begin{array}{l}(\%) \\
(13 \cdot 5)\end{array}$ & $11 \stackrel{(\%)}{(21 \cdot 2)}$ & $4 \stackrel{(\%)}{(7 \cdot 7)}$ \\
\hline Others & 48 & $29(60 \cdot 4)$ & $5(10.4)$ & $8(16 \cdot 7)$ & $6(12 \cdot 5)$ \\
\hline Total & 100 & $59(59 \cdot 0)$ & $12(12 \cdot 0)$ & $19(19 \cdot 0)$ & $10(10 \cdot 0)$ \\
\hline
\end{tabular}

Table 2 Data from Chapman-Smith and Crock (1977)

\begin{tabular}{|c|c|c|c|c|c|}
\hline & \multirow{2}{*}{$\begin{array}{l}\text { No. of } \\
\text { eyes }\end{array}$} & \multicolumn{4}{|c|}{ Improved visual acuity (Snellen chart) } \\
\hline & & $\geqslant 2$ lines & 1 line only & Unchanged & Worse \\
\hline $\begin{array}{l}\text { Total } \\
\text { ( } 2 \text { eyes } \\
\text { lost to } \\
\text { follow-up) }\end{array}$ & 34 & $10(29 \cdot 4 \%)$ & $9(26.5 \%)$ & $10(29 \cdot 4 \%)$ & $3(8 \cdot 8 \%)$ \\
\hline
\end{tabular}


15 monkeys (30 eyes) were used to study the effect of urokinase on clearance of vitreous haemorrhage, and an additional 4 monkeys ( 8 eyes) were used to study the toxicity of intravitreal urokinase. In our study the effect of urokinase was determined for the clearance of fresh, chronic, and repeatedly injected intravitreal blood. Urokinase was ineffective if injected as early as 24 hours after the intravitreal injection of blood or as late as 6 months thereafter. Following repeated injections of blood into the vitreous, clearance of blood occurred equally well after injection of either saline solution or urokinase. This result appeared to be due to mechanical agitation (and aspiration) of the vitreous and was not specific for urokinase. In fact, if vitreous was not aspirated, no clearing occurred.

Chapman-Smith and Crock concluded their article with the suggestion that urokinase 'should be used as a first line of attack in vitreous haemorrhage.... Their conclusion has doubtful validity, because, as their own data show, the effect of urokinase on acuity appears to be less favourable than that of surgical vitrectomy and because their data also show a high rate of complications from urokinase-for example, some eyes subsequently required cataract extraction, an undetermined number of eyes (follow-up not specified) developed transient glaucoma, and 22 of 34 eyes $(64 \cdot 7 \%)$ developed hypopyon. These complications represent a high price to pay for an unproved and possibly deleterious therapeutic approach. Sincerely yours,

GHOLAM A. PEYMAN

FELIPE U. HUAMONTE

MORTON F. GOLDBERG JEFF KOZIOL

Department of Ophthalmology,

University of Illinois,

Medical Center,

Chicago, USA.

\section{References}

Chapman-Smith, J. S., and Crock, G. W. (1977). Urokinase in the management of vitreous haemorrhage. British Journal of Ophthalmology, 61, 500-505.

Koziol, J., Peyman, G. A., Sanders, D. R., Vlchek, J., and Goldberg, M. F. (1975). Urokinase in experimental vitreous hemorrhage. Ophthalmic Surgery, 6, 79-82.

Peyman, G. A., Huamonte, F. U., and Goldberg, M. F. (1976a). One hundred consecutive pars plana vitrectomies using the vitrophage. American Journal of Ophthalmology, 81, 263-271.

Peyman, G. A., Raichand, M., Huamonte, F. U., Nagpal, K., Goldberg, M. F., and Sanders, D. R. (1976b).
Vitrectomy in 125 eyes with diabetic vitreous haemorrhage. British Journal of Ophthalmology. 60, 752-755.

SIR, We are grateful for the opportunity to comment on the letter from Dr Peyman and his associates.

The problem of visual acuity changes is not a new one. We all know that visual acuity is a finding which may show day-to-day variation. Because of this the generally accepted criterion for significant change has become 2 or more Snellen lines difference.

If one inspects the data given in their reference, Peyman et al. (1976a), and allows for such a change, then it is only possible to come up with the figures quoted by us (Chapman-Smith and Crock, 1977). We find it disconcerting that the writers should now produce new and different figures from their so-called raw data.

We note the point about their monkey experience. Our quoting the use of 4 is simply a reflection of over compression when editing the ultimate draft of our paper and we apologise to your readers for this. However, it should be obvious from our writing that we did indeed read the rest of the article (Koziol et al., 1975). Our experience does not suggest that vitreous aspiration is the basis of vitreous clearing in human eyes. Experiments with human urokinase in monkey vitreous may not be applicable to human eyes.

We acknowledge the remarks about complications, which must be viewed in the light of those quoted after vitrectomy. The percentage of lenses removed at vitrectomy greatly exceeds the operation rate in our urokinase patients. We wish to state again that hypopyon and glaucoma have been transient phenomena associated with our intravitreal injections of urokinase.

Finally, the most obvious point of all has been missed. If intravitreal urokinase injection does not work in a particular eye, it in no way bars a later attempt at surgical vitrectomy.

As a unit which has had a major part to play in the development of vitrectomy instruments we are naturally concerned that they be given a fair evaluation. Urokinase deserves as equally careful a prospective evaluation as vitrectomy in the management of unresolving vitreous haemorrhage.

Yours sincerely, J. S. CHAPMAN-SMITH G. W. CROCK

Department of Ophthalmology,

University of Melbourne,

Royal Victorian Eye and Ear Hospital,

Melbourne, Australia.

\section{Notes}

\section{Fight for Sight Awards}

Fight for Sight Inc announces that 1 March 1978 is the closing date for the receipt of applications to be funded during its 1978-79 awards year. Application forms, and the requirements for filing and funding pertinent to the Fight For Sight awards programme are being revised.
Therefore it is suggested that potential candidates contact the organisation for current forms and information. Request should be made in writing only to Fight for Sight Inc, 41 West 57 Street, New York, NY 10019, USA. 